\title{
Ideas centrales del pensamiento pedagógico político de Paulo Freire: dimensiones de análisis
}

\author{
Central ideas of Paulo Freire's political pedagogic thought: \\ analysis dimensions
}

\author{
María Verdeja Muñiz \\ Universidad de Oviedo
}

Recibido: $18 / 05 / 2017$

Aceptado: 28/06/2017

\begin{abstract}
Taking as a reference a theoretical model (Lens, 2001) we make an analysis around the central ideas of pedagogical political thought Freire (1921-1997). We offer an analysis focused on the pedagogical-political proposal of the Brazilian educator. For this we take as a starting point five dimensions of education: axiological; dialogical, political, gnoseological and methodological. This analysis will allow us to deepen in aspects of his pedagogical work as well as in the main lines of his thought. For the great Brazilian educator one of the main objectives of education is to transform the world around us into a world more just and kind to all. The educational process, necessarily, entails generating the possibilities of change and starting from the fact that change, although difficult, is possible.

KEY WORDS: Paulo Freire, dialogue, education, pedagogy, politics, dialogue.
\end{abstract}

\section{RESUMEN}

Tomando como referencia un modelo teórico (Lens, 2001) realizamos un análisis en torno a las ideas centrales del pensamiento pedagógico político Freire (1921-1997). Ofrecemos un análisis centrado en la propuesta pedagógicopolítica del educador brasileño. Para ello tomamos como punto de partida cinco dimensiones de la educación: axiológica; dialógica, política, gnoseológica y metodológica. Dicho análisis nos permitirá profundizar en aspectos de su obra pedagógica así como en las principales líneas de su pensamiento. Para el gran educador brasileño uno de los principales objetivos de la educación es conseguir transformar el mundo que nos rodea en un mundo más justo y amable para todos. El proceso educativo, necesariamente, conlleva generar las posibilidades de cambio y partir del hecho de que el cambio, a pesar de que es difícil, es posible.

PALABRAS CLAVE: Paulo Freire, diálogo, educación, pedagogía, política, diálogo. 


\section{Introducción}

Es importante comenzar diciendo que diversos autores (Macedo, 2000; Besalú, 2002, Torres, 2004) entienden que las ideas centrales del pensamiento de Paulo Freire y las aportaciones de su pedagogía admiten diversidad de lecturas. Es por este motivo que el educador brasileño siempre ha sido interpretado desde diferentes perspectivas (Torres, 2001; Arandia, 2004; Delgado Granados, 2010; Verdeja y González Riaño, 2016) y sus aportaciones pedagógicas admiten múltiples lecturas y por eso ha sido interpretado desde diferentes puntos de vista (Flecha, 1997; Torres, 2004; Gadotti, 2007, Verdeja, 2015). Las ideas filosóficas que fundamentan el pensamiento de Paulo Freire, son recordadas por diferentes autores (Blanco, 1982; Lens, 2001; Torres, 2004; Dussel, 2002; Gadotti, 2007; Santos-Gómez, 2008). A lo largo de la vida del educador brasileño hubo muchas personas que, de alguna manera, han contribuido a configurar su pensamiento, sus planteamientos pedagógicos, sus ideas y sus teorías.

El propio Freire también hace referencia a que sus planteamientos pedagógicos son el fruto de vivencias y experiencias personales (véase Freire, 1993 p. 17). Así pues, él mismo reconoce que las principales fuentes que inspiraron sus planteamientos, no fueron otras que las situaciones que le tocó vivir, esto es, sus vivencias personales en interacción con las personas; en definitiva: su gente más cercana, su familia, sus amistades, las conversaciones con la gente que le rodeaba. Freire elaboró sus planteamientos pedagógicos en coherencia con sus experiencias personales y en interacción con las personas que le rodearon. Esto queda claro, por ejemplo, en obras tan importantes como Pedagogía de la Esperanza (1993), obra que, tal y como indicaba Santos-Gómez (2008, p. 157), es totalmente coherente con su pedagogía pues en ella se puede observar que no hay una separación entre la vida y la teoría del educador brasileño.

A Freire hay diferentes temáticas que le preocupan y en ese sentido podemos observar que tales preocupaciones son temas recurrentes a lo largo de toda su obra. Desde la publicación en español de obras como Pedagogía del Oprimido en 1970, Freire habla de la concepción bancaria de la educación, la cual considera como un instrumento de opresión. Utiliza este término, "bancaria", para referirse a las prácticas opresoras que se dan tanto en la escuela como en el contexto general de lo político y lo social.

La crítica que hace Freire a la educación bancaria es una constante en toda su obra (Verdeja y González Riaño, 2016) pero es quizás en Pedagogía del Oprimido (1970) donde encontramos el mayor referente. Este modelo educativo, que considera a los estudiantes meros "depositarios" de contenidos anulando, así, la capacidad de reflexión y análisis crítico acerca de determinados contenidos, representa para Freire uno de los principales retos educativos (además de una gran preocupación). De este modo, -según Freire- la educación bancaria será domesticadora, los estudiantes serán meros depositarios y receptores de contenidos, con mayor facilidad se adaptarán al mundo y más lejos estarán de transformar la realidad. Esta actitud, nos alerta Freire, no fomenta la creatividad en el alumnado, sino que provoca en el propio alumnado el hábito de la pasividad y la indiferencia. Como alternativa a la educación bancaria - centrada en la transmisión de contenidosFreire apuesta por la educación problematizadora -centrada en el análisis crítico de temáticas y problemáticas sociales-:

Es así como, mientras la práctica "bancaria", como enfatizáramos, implica una especie de anestésico, inhibiendo el poder creador de los educandos, la educación problematizadora, de carácter automáticamente reflexivo, implica un acto permanente de desvelamiento de la realidad. La primera pretende mantener la inmersión, al segunda, por el contrario, busca la emersión de la conciencias, de la que resulta su inserción crítica en la (Freire, 1970, p. 86).

Freire reiteradamente insistió en que su análisis y su crítica a la educación bancaria no se referían únicamente al ámbito de la educación de adultos sino a la educación en su conjunto y, más allá de eso, a la sociedad en general a la cual dicha educación bancaria sirve de soporte. Por ello considero que una de las interesantes aportaciones de Freire guarda relación con esta cuestión, es 
decir, la necesidad de "alfabetización" de la población en general. Tal proceso de alfabetización, debe ser entendido como un aprendizaje necesario para toda la ciudadanía y debe estar orientado a "saber leer e interpretar el mundo en el que vivimos".

En una sociedad tan compleja y cambiante es fundamental saber interpretar la información que nos llega a través de los diferentes medios de comunicación así como saber hacer una lectura crítica de la misma. Este proceso de alfabetización consiste, principalmente, en aprender a leer de forma crítica el mundo y la realidad que nos rodea. Sin embargo, desde el punto de vista de Freire, esta tarea de alfabetización de la sociedad es tremendamente difícil. El problema -como indica Freire- radica, principalmente, en que procedemos de un sistema educativo basado en un modelo de educación bancaria, es decir, un sistema educativo que fomenta la transmisión de contenidos y no la reflexión crítica de los mismos. Dicho proceso de transmisión se hace, principalmente, a través del desarrollo de contenidos curriculares descontextualizados que no analizan problemáticas actuales y que son impartidos con una metodología que tampoco fomenta la reflexión del alumnado o lo que es lo mismo, un modelo de escuela donde se impone una única visión del mundo.

Como alternativa a la educación bancaria propone y defiende Freire la educación problematizadora superando, así, la contradicción educador-educando. Desde esta concepción de la educación se entiende que estudiantes y docentes son sujetos activos y, por tanto, están en proceso de construcción de la historia. Desde esta perspectiva que nos plantea Freire el proceso educativo debe contribuir a formar ciudadanos críticos y participativos. Se considera que estudiantes y docentes son sujetos activos en proceso continuo de construcción de la historia y pueden ser capaces de problematizar la realidad y mirar críticamente el mundo que les rodea.

Es por eso que considero que Freire nos ofrece una nueva visión y debemos estar atentos a la importancia de su discurso. En relación con esta cuestión Besalú (2002) señala que frente al discurso de la reproducción teóricamente defectuoso y estratégicamente paralizador, se alza el discurso de la producción de conocimiento que habla de la pedagogía como praxis política y ética, siendo Freire uno de los que mejor ha explicado esta posición. Recojo aquí algunas ideas de Freire que, como apuntaba Besalú (2002, p. 40-41), van en la línea de la construcción del conocimiento y no en la reproducción:

- Enseñar no es transferir conocimiento, ni dar forma a un cuerpo indeciso, sino crear las posibilidades de su producción o de su construcción, enseñar exige respetar los saberes, la identidad y la autonomía de los educandos y discutir con ellos la razón de sus saberes.

- Enseñar exige saber escuchar y respetar la lectura del mundo de los educandos, porque es la manera correcta de intentar entender el mundo de una forma más crítica, lo contrario es antidemocrático.

- Enseñar exige conocer que somos seres condicionados, pero no determinados: la concientización no es sino el esfuerzo crítico de conocimiento de los obstáculos que dificultan la tarea histórica de cambiar el mundo. Enseñar exige la convicción de que el cambio es posible: no somos solo objetos de la Historia, sino también sujetos, el futuro es problemático, pero inexorable.

- Enseñar exige comprender que la educación es una forma de intervención en el mundo, reconocer que la educación es ideológica. Educar exige querer bien a los educandos, porque este trabajo se realiza con personas, lo que demanda un alto nivel de capacitación científica y de responsabilidad ética.

Sin embargo, más allá de este discurso que ya de por sí es muy coherente, considero que las aportaciones de Freire representan un planteamiento pedagógico-político mucho más complejo e interesante y por eso merece toda nuestra atención. La perspectiva que a continuación ofrezco en el presente trabajo nace de la lectura de una parte de la obra escrita de Freire y representa una interpretación de la misma. En esta ocasión pretendo indagar en un aspecto que desde el punto de vista de algunos autores no ha sido especialmente abordado y para ello me voy a centrar en lo que Lens (2001) denomina: "carácter sistémico de su propuesta". 
A continuación me propongo realizar un análisis de las ideas y pensamiento pedagógicopolítico de Freire. Para realizar dicho análisis lo haré tomando como referencia el enfoque teórico de Lens (2001) quien realiza un análisis sistémico de la propuesta de Freire tomando como punto de partida cinco dimensiones de la educación: axiológica, dialógica, política, gnoseológica y metodológica. Según afirma Lens (2001) existe una relación dialéctica entre todas ellas y con gran coherencia representan lo que él denomina: "edificio teórico de su sistema de pensamiento".

\section{Fundamentación teórica}

El análisis de Lens (2001) parte de cinco dimensiones de la educación que son elaboradas y reelaboradas por Freire a lo largo de su extensa obra. Las dimensiones a las que se refiere Lens (2001) son las siguientes:

1. Dimensión axiológica. Para Freire uno de los principales objetivos de la educación es la transformación de un mundo desigual e injusto en un mundo ético y profundamente solidario. El proceso educativo conlleva generar las posibilidades de cambio y partir del hecho de que aunque el cambio es difícil, es posible. Esta es, sin duda, una de sus grandes preocupaciones y un tema recurrente a lo largo de toda su obra.

2. Dimensión dialógica. Freire muestra el diálogo como una condición indispensable para la humanización del mundo. Esta concepción dialógica es, en sí, la esencia del intercambio intercultural. Se parte de una concepción antropológica de la cultura y se presenta la diversidad cultural como algo enriquecedor de las culturas sin que una cultura se imponga a otras culturas.

3. Dimensión política. Freire alude principalmente a la imposibilidad de considerar la práctica educativa como una actividad neutra, sobre todo si tenemos en cuenta que la educación tiene fuertes componentes socio-políticos. No es posible, por tanto, considerar que la educación es una actividad que pueda ser abordada exclusivamente desde una dimensión técnica y metodológica -y por tanto neutra- puesto que tiene componentes sociales, económicos, políticos y culturales, etc.

4. Dimensión gnoseológica. Freire considera que la educación representa un acto de conocimiento en el marco de objetivos socioeducativos dirigidos por el ideario de la formación de personas críticas y con autonomía para pensar y tomar decisiones. Para ello es fundamental dos cuestiones: partir del hecho de que la educación no es neutral y utilizar el diálogo como principal método de construcción de conocimiento. La dimensión gnoseológica de la educación se refiere a la construcción de una teoría del conocimiento coherente con la "dialoguicidad" y la "politicidad" de la educación.

5. Dimensión metodológica. Esta dimensión solo puede comprenderse en el marco significativo de las relaciones con otras dimensiones y mantiene una relación dialéctica con todas ellas, pero, en especial, con la dimensión gnoseológica. De la conjunción coherente de estos principios Freire extrae la idea de "diálogo", al que le atribuye un carácter fundante de la educación. Freire propone un diálogo entre profesorado y alumnado en el que los docentes no son los depositarios del saber ni los estudiantes meros receptores de saberes acumulados, sino que el diálogo se constituye como acto cognoscitivo en el que ambos -educador y educando- aprenden.

Desde esta perspectiva que estamos analizando (Lens, 2001) el sistema pedagógico-político de Freire se presenta como una unidad coherente de principios y métodos donde diferentes dimensiones aparecen interrelacionadas constituyendo una propuesta metodológica que integra las principales sus ideas pedagógicas. Estas dimensiones según Lens (2001) están relacionadas entre sí y por ello no pueden ser entendidas de forma aislada sino que adquieren su pleno significado cuando hablamos de las conexiones que existen entre ellas - por eso hablamos de sistema-. Tales dimensiones lejos de permanecer estáticas, son continuamente elaboradas y re-elaboradas por el propio Freire a lo largo 
de toda su obra. Relacionado con el carácter sistémico de la propuesta pedagógico-política de Freire, es el hecho de que no es posible parcializarla, es decir, aceptar algunos elementos y rechazar otros por ejemplo, aceptando la metodología y rechazando los presupuestos filosófico-teóricos. Se puede afirmar que existe una relación dialéctica entre todas las dimensiones.

Veamos en la siguiente figura 1 cómo tales dimensiones se relacionan en lo que Lens (2001) considera un sistema coherente de fundamentación:

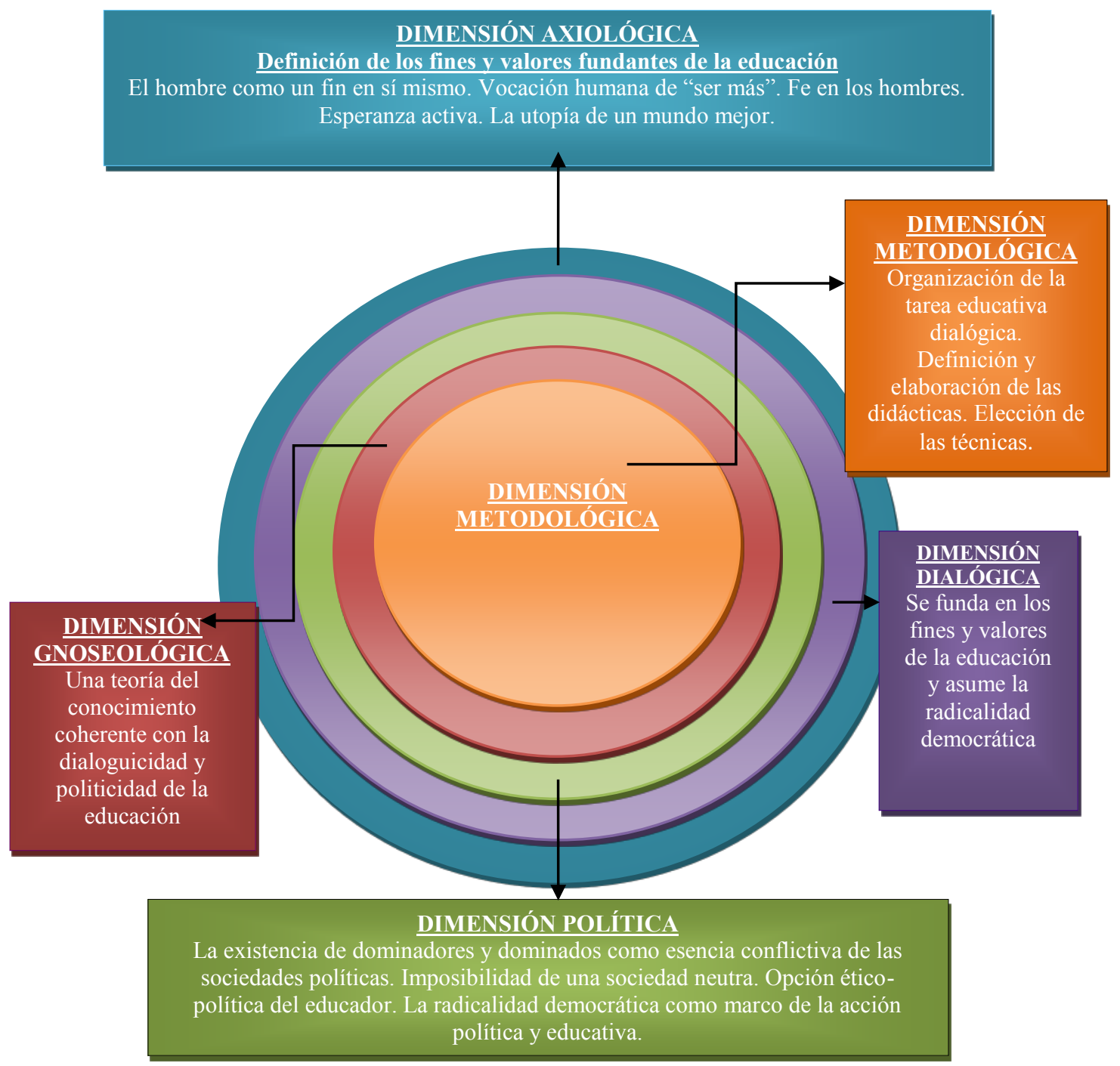

Figura 1. El sistema pedagógico-político de Paulo Freire como unidad coherente de principios y métodos. Fuente: Lens (2001, p. 26)

\section{1) Dimensión axiológica}

Para hacer nuestro análisis, resulta imprescindible preguntarse: ¿cuáles son los principales objetivos de la propuesta de Paulo Freire? La dimensión axiológica tiene que ver con los fines y valores de la educación. Según Lens (2001) la finalidad de la propuesta educativa de Freire se podría resumir en la búsqueda de la humanización de las personas. 
Este es, para Freire, el objetivo primordial de la educación, es decir, la educación se constituye como instrumento de cambio para lograr un mundo más social y humano y profundamente ético y solidario. Ninguna de las demás dimensiones puede ser entendida al margen de este objetivo, fundamental que Freire le otorga a la práctica educativa. Paulo Freire (1993) hace una dura crítica a cómo está configurado el mundo, al dictado de un sistema capitalista, en el que hay una brutal desigualdad entre los seres humanos, el reparto de la riqueza o a la discriminación. Nuestro autor se sorprende del mundo en el que vivimos y cómo se han "naturalizado" diferentes situaciones de tal forma que ya no nos sorprendemos de ellas. El educador brasileño nos alerta de que tenemos que estar atentos y sorprendernos de estas situaciones:

Qué excelencia será esa que puede "convivir con más de mil millones de habitantes en el mundo en desarrollo que viven en la pobreza", por no decir en la miseria. Por no hablar tampoco de la casi indiferencia con que convive, con bolsones de pobreza y miseria en su propio cuerpo, el mundo desarrollado. Qué excelencia será esa que duerme en paz con la presencia de un sinnúmero de hombres y mujeres cuyo hogar es la calle, y todavía dice que es culpa de ellos y ellas estar en la calle. Qué excelencia será esa que poco o nada lucha contra las discriminaciones de sexo, de clase, de raza, como si negar lo diferente, humillarlo, ofenderlo, menospreciarlo, explotarlo, fuera un derecho de los individuos o de las clases, de las razas o de un sexo en posición de poder sobre otro. Qué excelencia será esa que registra tranquilamente en estadísticas los millones de niños que llegan al mundo y no se quedan, y cuando se quedan se van temprano, en la infancia todavía, y si son más resistentes y consiguen quedarse, pronto se despiden del mundo (p. 90).

Para ello Freire (2010) hace hincapié en que es absolutamente necesario hacer una lectura crítica del mundo: "La lectura crítica del mundo es un quehacer pedagógico-político indivisible del quehacer político-pedagógico, es decir, de la acción política que envuelve la organización de los grupos y las clases populares para intervenir en la reinvención de la sociedad" (p. 53). Podemos afirmar que para Freire el principal objetivo de la educación es la transformación de un mundo desigual e injusto en uno mejor, menos feo y malvado. Para conseguir ese objetivo de la educación los docentes juegan un papel fundamental. Según Freire (2010) los educadores y educadoras debemos extraer todas las consecuencias de este valor y objetivo fundamental de la educación e intentar ser coherentes en todo momento con dicho objetivo. Para Freire (2010) hombres y mujeres somos seres inacabados que se necesitan mutuamente para conocer y transformar el mundo, a la vez que se construyen como sujetos. La educación tiene su razón de ser en el carácter inacabado de los seres humanos: "La educación tiene sentido porque el mundo no es necesariamente esto o aquello, porque los seres humanos son proyectos y, a la vez, pueden tener proyectos para el mundo" (p. 50).

\section{1) Dimensión dialógica}

Con relación a la dimensión dialógica se puede señalar que, según Lens (2001), está en conjunción con la posición humanista y ético-democrática de Freire. Freire (1970) considera que el diálogo es una exigencia existencial y lo entiende como principal método de construcción de conocimiento. De esta forma debemos entender la dimensión dialógica de la educación como un recurso metodológico necesario para construir conocimiento. Freire apuesta por emplear en las escuelas una metodología basada en el diálogo como instrumento facilitador del aprendizaje así como por el empleo de una metodología participativa y colaborativa, donde el docente debe desempeñar un papel de facilitador y mediador en los procesos de enseñanza aprendizaje. Pero, además, según Freire (1970) el diálogo auténtico representa un papel mucho más importante porque implica el reconocimiento del otro así como el reconocimiento de uno mismo en el otro: 
El diálogo es una exigencia existencial. Y siendo el encuentro que solidariza la reflexión y la acción de sus sujetos encauzados hacia el mundo que debe ser transformado y humanizado, no puede reducirse a un mero acto de depositar ideas de un sujeto en el otro, ni convertirse tampoco en un simple cambio de ideas consumadas por sus permutantes (p. 99).

Paulo Freire (1970) muestra el diálogo como una condición indispensable para la humanización del mundo: "Existir, humanamente, es "pronunciar" el mundo, es transformarlo. El mundo pronunciado, a su vez, retorna problematizado a los sujetos pronunciantes, exigiendo de ellos un nuevo pronunciamiento" (p. 98).

Esta concepción dialógica es, en sí, la esencia del intercambio intercultural, puesto que parte de la diversidad como algo enriquecedor, sin que una cultura se imponga a las demás: "dado que el diálogo es el encuentro de los hombres que pronuncian el mundo, no puede existir una pronunciación de unos a otros. Es un acto creador. De ahí que no pueda ser mañoso instrumento del cual eche mano un sujeto para conquistar a otro" (Freire, 1970, p. 99).

Una condición indispensable para que se produzca el diálogo, es la humildad, como así señala Freire (1970): "No hay, por otro lado, diálogo si no hay humildad (p. 101). Freire (1994) propone el diálogo como método de conocimiento orientado a conocer la realidad que nos rodea buscando, al mismo tiempo, formas de entender y explicar dicha realidad. Para ello es fundamental hacer una análisis crítico de la realidad que nos permita comprender dicha realidad: "Para que el diálogo sea un método de verdadero conocimiento, los sujetos de conocimiento deben abordar la realidad científicamente buscando las conexiones dialécticas que explican la forma de la realidad" (p. 76). Para que se produzca el verdadero diálogo es necesario que exista humildad. Pero, además, también son necesarias otras virtudes sin las cuales es imposible que éste pueda darse, así pues, además de la humildad, -como señala Freire- son esenciales virtudes tales como: la coherencia, la tolerancia y la justicia. Desde este enfoque (Freire, 1993) se presenta el diálogo como la forma de superar los fundamentalismos, de posibilitar el encuentro entre iguales y diferentes.

Para Freire (1970) la verdadera educación es diálogo: "La educación debe comenzar por la superación entre la contradicción educador-educando. Debe fundarse en la conciliación de sus polos, de tal manera que ambos se hagan, simultáneamente, educadores y educandos" (p. 73). Freire (1993) propone un diálogo entre profesorado y alumnado en el que los docentes no son los depositarios del saber ni el alumnado mero receptor de saberes acumulados, sino que se constituye como un proceso en el que ambos -docentes y estudiantes- aprenden; un diálogo por tanto que, supone el reconocimiento del otro:

El diálogo entre profesoras o profesores y alumnos o alumnas no los convierte en iguales, pero marca la posición democrática entre ellos o ellas. Los profesores no son iguales a los alumnos por $\mathrm{n}$ razones, entre ellas porque la diferencia entre ellos los hace ser como están siendo. $\mathrm{Si}$ fuesen iguales, uno se convertiría en el otro (p. 112).

Freire formula una propuesta basada en el diálogo resaltando la importancia de que el diálogo se desarrolle con unas condiciones tales como: rigor, coherencia, humildad y desde una perspectiva democrática. Además, tales condiciones son imprescindibles para que se produzca el encuentro entre educador y educando. A partir de este proceso de comunicación dialógica, educador y educando pueden construir conocimiento (Verdeja y González Riaño, 2016).

\section{2) Dimensión política}

La educación tiene naturaleza política en todo el mundo tal y como señala Freire (1994) y por tanto no podemos negar el carácter político de la educación ni tampoco su trasfondo ideológico. 
Partiendo de la base de que la educación no es neutral se revela, por tanto, la dimensión política e ideológica de la educación. Si queremos que haya cambios, es necesario que exista voluntad política de cambio.

Con relación a la dimensión política Lens (2001) señala que Freire alude principalmente a la imposibilidad de considerar la práctica educativa como una actividad neutra dado que la educación tiene fuertes componentes socio-políticos.

Partiendo de la base de que la educación no es neutral se revela la dimensión política e ideológica de la educación. Como señala Freire no es posible asumir la educación como una actividad que pueda ser abordada exclusivamente desde una dimensión meramente técnica o metodológica $-\mathrm{y}$ por tanto neutra- puesto que tiene componentes sociales, económicos, políticos y culturales, etc (Verdeja y González Riaño, 2016).

Con relación a los contenidos Freire (1993) señala lo siguiente: "El problema fundamental, de naturaleza política, está coloreado con tintes ideológicos, a saber, quién elige los contenidos, a favor de quién y de qué estará su enseñanza, contra quién, a favor de qué, contra qué” (p. 105).

Según Lens (2001) dentro de esta dimensión política también estaría incluida la dimensión dialógica de la educación que no puede ser partidaria ni doctrinal sino que debe mostrarse auténticamente ética y política, es decir, realizada para favorecer cuestiones tan importantes como la igualdad de oportunidades, la defensa del carácter público y popular de la educación, la defensa y promoción de los que menos tienen, la lucha contra todo tipo de discriminación y por la vigencia plena de los derechos humanos.

\section{3) Dimensión gnoseológica}

Con relación a la siguiente dimensión, la gnoseológica, como señala Lens (2001) es necesario entender tal dimensión de la educació en relación con las dimensiones dialógica y política.

Freire (1993) era totalmente consciente de que la educación, por sí sola, no es suficiente para el cambio y la transformación del mundo pero, también señala que es necesaria para lograr cambios: "Sin embargo la educación, en cuanto práctica reveladora, gnoseológica, no efectúa por sí sola la transformación del mundo, aunque es necesaria para ella" (p. 29). Nos detenemos en una interesante reflexión que realiza Freire (1993, p. 98-99) en la que hace alusión a un pequeño texto que escribió en 1974 con motivo de un encuentro en Ginebra en el que participó junto a Iván Illich. En dicho encuentro ambos autores retomaban los conceptos de "desescolarización" (Illich, 1974) y "concientización" (Freire, 1969).

Dicha reflexión realizada por Freire (1993) nos parece especialmente relevante para explicar determinados aspectos de la dimensión gnoseológica pero, también porque el propio Freire aclara algunas cuestiones relacionadas con el término "concientización" haciendo una autocrítica. Así pues, con relación a dicho término, concreta lo siguiente:

Así como el ciclo gnoseológico no termina en la etapa de la adquisición del conocimiento ya existente, pues se prolonga hasta la fase de creación de un nuevo conocimiento, la concientización no puede parar en la etapa de la revelación de la realidad. Su autenticidad se da cuando la práctica de la revelación de la realidad constituye una unidad dinámica y dialéctica con la práctica de transformación de la realidad (Freire, 1993, p. 98-99).

Pero lo más interesante, lo encontramos a continuación, cuando Freire (1993) expone:

Creo que es posible y necesario hacer algunas observaciones a partir de estas reflexiones. Una de ellas es la crítica que me hago a mí mismo de haber tomado el momento de revelación de la realidad social como una especie de motivador psicológico de su transformación a considerar el proceso de concientización en La educación como práctica de la libertad. Mi error no estaba, obviamente, en reconocer la importancia fundamental del conocimiento de la realidad 
en el proceso de su transformación. Mi error consistió en no haber tomado esos polos (conocimiento de la realidad y transformación de la realidad) en su dialecticidad. Era como si revelar la realidad significase su transformación (p. 99).

Freire matiza que el simple hecho de conocer la realidad no significa que automáticamente tal realidad pueda ser transformada. Apela a la relación dialéctica que existe entre el conocimiento de la realidad y la transformación de la misma. Conocer la realidad no implica que automáticamente se produzca el cambio y la transformación de una realidad concreta -por ejemplo la pobreza- sino que existe una relación dialéctica ente ambas realidades. Freire (1997) señala que no debemos olvidarnos de la relación dialéctica que existe entre conocer la realidad y transformar la realidad: "La transformación del mundo implica establecer una dialéctica de la situación deshumanizante y el anuncio de su superación, que es, en el fondo, nuestro sueño" (p. 77). Tal relación dialéctica la hemos reflejado en la siguiente figura 2 :

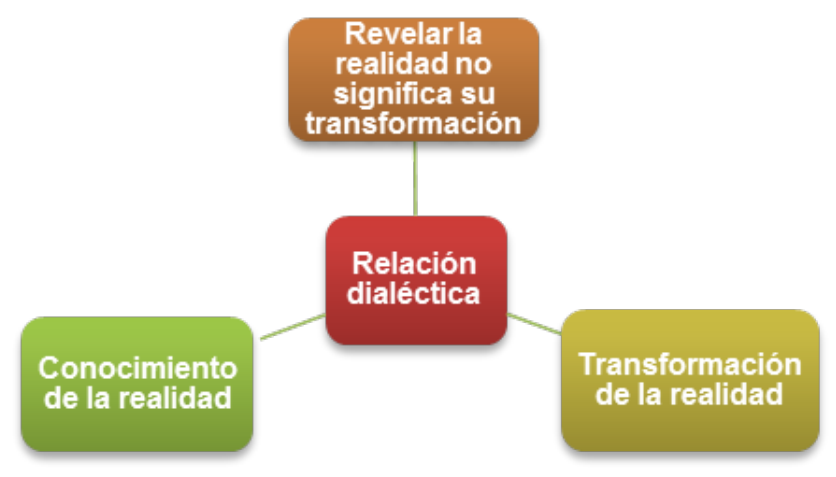

Figura 2: Relación dialéctica entre conocimiento y transformación de la realidad. (Elaboración Propia)

\section{4) Dimensión metodológica}

Por último, con relación a la dimensión metodológica Lens (2001) señala que solo puede comprenderse el significado de las otras dimensiones (axiológica, dialógica, política, gnoseológica) ya que plantea la educación como un acto de conocimiento en el que los educadores aprenden a partir de la revisión de su propia práctica docente.

Para Freire es fundamental un sistema de evaluación crítica que esté orientado a la mejora de la práctica docente. Para ello necesitamos utilizar diversidad de instrumentos y procedimientos de evaluación que nos permitan hacer un seguimiento de la propia práctica docente. Tales procedimientos -sugiere Freire- deben estar orientados a reducir la distancia entre lo que decimos y lo que hacemos, es decir, a conseguir la coherencia entre la teoría y la práctica. Para reducir la distancia entre lo que decimos y lo que hacemos Freire (1993) hace referencia a la evaluación crítica de la práctica docente. Dicho ejercicio de evaluación critica, va revelando la necesidad de una serie de virtudes. Desde la perspectiva de Freire, tales cualidades - de los docentes- son construidas por cada uno de nosotros al imponernos el esfuerzo de disminuir la distancia entre lo que decimos y lo que hacemos. Freire (1969) considera que la dialoguicidad es la esencia de la educación como práctica de la libertad. El carácter dialógico de la educación es el principio que regula las relaciones entre educadores y educandos limitando los excesos autoritarios que anulan la libertad.

Como así refieren otros autores (Posada, 2007) tal sustantividad democrática propuesta por Freire es una pedagogía del diálogo cultural y una propuesta pedagógica que implica una apertura a la diversidad, como así explica el propio Freire (1993): "En cuanto relación democrática, el diálogo es la posibilidad de que dispongo para, abriéndome al pensar de los otros, no perecer en el aislamiento" (p. 114). 


\section{Carácter sistémico de la propuesta de Paulo Freire}

Una vez que se han abordado en el marco teórico las cinco dimensiones de análisis, nos parece interesante insistir y clarificar cómo a partir de tales dimensiones emerge el carácter sistémico de la propuesta de Freire. Lens (2001) nos presenta el sistema pedagógico-político de Paulo Freire como una unidad coherente de principios y métodos en el que todas las dimensiones están relacionadas entre sí (por eso considera que conforma una unidad coherente de principios y métodos). Todas las dimensiones está interrelacionadas entre sí y ninguna se pude entender de forma independiente o aislada de las demás. Tales dimensiones, lejos de permanecer estáticas, son continuamente elaboradas y re-elaboradas por el propio Paulo Freire en toda su obra. Considero que Lens (2001) considera que la propuesta de Freire tiene un carácter sistémico por diversos motivos. Uno de ellos porque existe una coherencia interna en todas las dimensiones así como en la relación que se establece entre todas ellas, es decir, todas están relacionadas entre sí. Consideramos que ésta es una interesante aportación de Lens (2001) porque analiza las aportaciones de la pedagogía de Paulo Freire como una propuesta que contiene una gran coherencia interna.

A largo de toda su obra, y sobre todo a lo largo de su experiencia vital, el educador brasileño ha mostrado una preocupación por los otros. Acertó a colocar al oprimido (excluido) en el escenario de la historia y destacó la importancia que tiene el saber cotidiano de un grupo social, al tiempo que hizo ver que la exclusión es una forma de opresión. Freire entiende que no es posible que exista una sociedad neutra y aboga por la radicalidad democrática como marco de acción política y educativa. Es necesario agudizar nuestra capacidad crítica para sorprendernos y preguntarnos el porqué de las cosas que suceden en nuestro mundo. Esto guarda relación con la dimensión política y la dimensión axiológica. Por este motivo, Freire hace una dura crítica al neoliberalismo en cuanto que consigue "naturalizar" la desigualdad y a su ideología inmovilizante en cuanto que manifiesta que no hay nada que podamos hacer para cambiar las cosas. Por este motivo, una constante en toda su obra es llamar nuestra atención para recordarnos que la desigualdad no es natural (ni neutral). Para Freire $(1970,1997,2010)$ el principal valor y objetivo de la educación es la transformación de un mundo desigual e injusto en uno ético y profundamente solidario. La educación, para Freire, no es un paquete de técnicas y métodos que se pueden aplicar sin consecuencias prescindiendo de los contextos sociales y políticos y de las estructuras y entramados de poder siempre existentes. La educación tampoco es la palanca de los cambios sociales, precisamente por su dependencia del campo sociopolítico, como así recuerda Gadotti (2007):

La educación no lo es todo, solía decir. No podemos ser ingenuos si lo que queremos es tener una práctica educativa crítica y transformadora. Paulo Freire no puede ser acusado de ser un optimista ingenuo. No hay práctica educativa, como cualquiera de las otras prácticas, que escape a los límites. Límites ideológicos, epistemológicos, políticos, económicos, culturales (...). Creo que la mejor afirmación para definir el alcance de la práctica educativa frente a los límites a los que ella se somete es la siguiente: sin poderlo todo, la práctica educativa puede logar algo (p. 35).

El mismo Paulo Freire (1997) lo expresa así:

Ni la educación es una fuerza imbatible al servicio de la transformación de la sociedad, porque yo así lo quiera, ni tampoco la perpetuación del statu quo porque el dominante así lo decrete. El educador y la educadora críticos no pueden pensar que, a partir del curso que coordinan o del seminario que dirigen, pueden transformar al país. Pero pueden demostrar que es posible cambiar. Y esto refuerza en él o en ella la importancia de su tarea políticopedagógica (p. 108).

Freire nos presenta una visión de la educación cimentada en el rigor, la investigación, la actitud crítica, el riesgo, la humildad, el buen juicio, la tolerancia, la alegría, la curiosidad, la competencia... y otras virtudes, todas ellas, bañadas por la esperanza. Para Freire es fundamental el papel que desempeñan 
los docentes y en numerosas ocasiones hace referencia a las virtudes inherentes a la práctica docente, destacando, entre otras, la tolerancia, la ética universal, la coherencia, etc. Esto tiene que ver con la dimensión gnoseológica en cuanto que Freire nos presenta una teoría del conocimiento coherente con la dialogicidad y politicidad de la educación. Para el pedagogo brasileño uno de las principales finalidades de la educación es conseguir un mundo más amable y justo para todos los seres humanos, es decir: la utopía de un mundo mejor

La importancia de las exigencias planteadas para los docentes la podemos encontrar en Freire (1997) donde reflexiona acerca de las orientaciones que debieran guiar la práctica. Esto entroncaría con la dimensión metodológica. Desde una reflexión sobre su práctica pedagogía y a través de un lenguaje accesible y didáctico, Freire hace referencia a los saberes necesarios para la práctica educativo-crítica con base en una ética-pedagógica. Freire hace alusión a cuestiones metodológicas tan importantes como el rigor, la investigación, la actitud crítica, el riesgo, la humildad, el buen juicio, la tolerancia, la alegría, la curiosidad, la competencia... y otras virtudes, todas ellas, bañadas por la esperanza. Freire se aproxima nuevamente a algunas cuestiones como la inconclusión del ser humano y su inserción en un permanente movimiento de búsqueda y vuelve a insistir en la idea de que enseñar no es transferir conocimientos. También realiza una crítica a la ideología neoliberal por su discurso fatalista que rechaza el sueño y la utopía:

Es en ese sentido como vuelvo a insistir en que formar es mucho más que simplemente adiestrar al educando en el desempeño de destrezas. Y por qué no mencionar también la casi obstinación con que hablo de mi interés por todo lo que respecta a los hombres y las mujeres, asunto del que salgo y al que vuelvo con el gusto de quien se entrega a él por primera vez. De ahí la crítica permanente que llevo en mí a la maldad neoliberal, el cinismo de su ideología fatalista y su rechazo al sueño y a la utopía (Freire, 1997, p. 16).

El pedagogo brasileño siempre criticó el excesivo uso de ejercicios repetidos que sobrepasan el límite razonable en cuanto dejan de lado una educación crítica de la curiosidad. Afirma que los docentes seguimos dando respuestas a preguntas que no nos fueron hechas, sin subrayar a los alumnos la importancia de la curiosidad. Llegados a este punto es preciso recordar que una de las preocupaciones de nuestro auto e lo que él denomina la "educación bancaria" y que considera a los estudiantes y docente meros depositarios de contenidos. Freire (1994) propone el diálogo como método de construcción de conocimiento. Considera que dicho proceso dialógico debe estar orientado al conocimiento de la realidad que nos rodea buscando, al mismo tiempo, formas de entender y explicar dicha realidad: "Para que el diálogo sea un método de verdadero conocimiento, los sujetos de conocimiento deben abordar la realidad científicamente buscando las conexiones dialécticas que explican la forma de la realidad" (p. 76). Esto, en esencia, representa la dimensión dialógica y la dimensión metodológica. Freire entiende el diálogo como un método de construcción de conocimiento y por ello critica con dureza a la educación bancaria a la que considera una forma de opresión. Como alternativa propone una educación problematizadora que considera que los docentes y estudiantes son sujetos activos en el proceso de construcción de conocimiento y donde el diálogo representa un método de conocimiento orientado a satisfacer la curiosidad profunda (tanto de docentes como de estudiantes). Para Freire la educación es diálogo y debe estar orientado a despertar y fomentar la curiosidad profunda por el mundo que nos rodea. Según Freire el diálogo es una exigencia existencial y lo entiende como principal método de conocimiento para trabajar en las escuelas. Dicho modelo educativo entiende el diálogo como método en la construcción de conocimiento. Asume la comprensión de la educación como un acto de conocimiento en el marco de objetivos pedagógicos dirigidos por el ideario de la formación de sujetos críticos y realmente autónomos. Significa, además, una educación centrada en las necesidades de los seres humanos para buscar soluciones y mejora. 


\section{Algunas reflexiones finales}

Paulo Freire tiene una curiosidad profunda por diversas temáticas sobre las que incide en toda su extensa producción ensayista. A modo de reflexión y teniendo en cuenta lo mencionado anteriormente, pasaré a exponer en el presente apartado algunas ideas centrales de su pensamiento:

Su pedagogía continúa siendo válida en nuestros días pero, sobre todo, continúa siendo válida en las escuelas. La escuela y los sistemas educativos actuales, ante la generalización de la información en la sociedad, se encuentran frente a nuevos y grandes desafíos. Su pedagogía continúa siendo válida en el mundo actual no solo porque aún hay muchas desigualdades en el mundo sino porque, además, responde a necesidades fundamentales de la educación actual.

La pedagogía de Freire propone que todos los seres humanos hagamos una lectura crítica del mundo en el que vivimos. Pero, teniendo presentes los planteamientos del autor, debemos hacer una lectura del mundo que no genere desesperanza. Las posibilidades de transformación del mundo en el que vivimos las tenemos en nuestras manos. Esta es una tarea pendiente y de la que nos debemos responsabilizamos todos los seres humanos ya que como sujetos activos tenemos en nuestras manos las posibilidades del cambio y de la transformación.

Paulo Freire hace una apuesta firme por la educación problematizadora que, desde una perspectiva crítica fomenta el diálogo, el debate y la reflexión acerca de los problemas actuales y se muestra como la alternativa a la "educación bancaria" que considera al alumnado en depositarios de contenidos anulando, así, la capacidad de las personas para pensar y reflexionar y que además fomenta una ideología fatalista e inmovilizante frente a los problemas sociales.

La educación debe hacer creíble tales posibilidades de cambio y transformación, por eso para Freire es fundamental la esperanza. Los educadores y educadoras deben tener esperanza y creer en la posibilidad de cambio y de transformación. Freire habló de la esperanza como una cuestión inherente a la práctica docente, recordando, al mismo tiempo, que los educadores y educadoras sin esperanza contradicen su propio ser y su propia práctica.

Su legado es amplio y diverso, pero, a nuestro juicio, hay una cuestión fundamental que hoy en día se convierte en un requerimiento de primer orden: la necesidad de impulsar la lectura crítica del mundo. Esto, metafóricamente hablando, representaría una campaña de alfabetización de adultos y es, al mismo tiempo, un tema pendiente.

A lo largo y ancho del planeta, en los lugares y culturas más diversos, cada quien fue encontrando en Freire, esencialmente, lo que necesitaba y lo que quería encontrar. Y aquí radica, quizás, parte de la explicación acerca de la multiplicidad de lecturas de su obra. Para Torres (2004) poco importa si unos entendieron mejor a Freire que otros, si hubo quienes comprendieron realmente su pensamiento o no. Quizás, la contribución mayor de Paulo Freire está en haber logrado comunicarse y conectarse con mucha gente, ayudarles a saber que existe algo llamado educación y algo llamado pobreza/marginación/opresión y que existe una relación entre ellas.

Para Torres (2001) hay buenas razones por las cuales, en la pedagogía en la actualidad, podemos estar con Freire o contra Freire, pero no sin Freire. Como también nos recuerda el profesor Moacir Gadotti, actual director del Instituto Paulo Freire, en São Paulo, Brasil, no se le puede dar continuidad a Paulo Freire sin reinventarlo. Para esta tarea no designó a una persona o institución en particular. Esta tarea nos la dejó a todas las personas, es decir, a todos los seres humanos comprometidos con la causa de los oprimidos. 
Referencias bibliográficas

Arandia, M. (2004). La formación de educadores y educadoras desde la mirada de Freire. Revista Interuniversitaria de Formación del Profesorado, 18 (2), 59-77.

Besalú, X. (2002). Diversidad cultural y educación. Madrid: Editorial Síntesis S.A.

Blanco, R. (1982). La pedagogía de Paulo Freire. Ideología y método de la educación liberadora. Madrid: ZeroZyx.

Delgado Granados, P. (2010). Educación, democracia y ciudadanía en el siglo XXI desde el proyecto político educativo de Paulo Freire. Revista Fuentes, 10, 143-156.

Dussel, E. (2002). Ética de la liberación en la edad de la globalización y de la exclusión. Madrid: Ediciones Trotta.

Flecha, J.R. (1997). El Freire que conocí. Cuadernos de Pedagogía, 259, 90-91.

Freire, P. (1969). Educación como práctica de la libertad. [Edición revisada, septiembre 2009]. Madrid. España: Siglo XXI de España Ediciones S.A.

Freire, P. (1970). Pedagogía del oprimido. 21 ${ }^{a}$ Ed. Madrid. España: Siglo XXI Ediciones S.A.

Freire, P. (1993). Pedagogía de la Esperanza: un reencuentro con la pedagogía del oprimido. $7^{\mathrm{a}}$ Ed. Madrid: Siglo XXI Editores S.A. de C.V.

Freire, P. (1994). La naturaleza politica de la educación. Barcelona: Editorial Planeta De Agostini S.A.

Freire, P. (1997). Pedagogía de la Autonomía. Saberes necesarios para la práctica educativa. $11^{a}$ Ed. Madrid: España. Siglo XXI editores. S.A. de C. V.

Freire, P. (2010). Pedagogía de la indignación. $3^{\mathrm{a}}$ Ed. Madrid: Ediciones Morata S.L.

Gadotti, M. (2007). La escuela y el maestro Paulo Freire y la pasión de enseñar. São Paulo. Brasil. Editorial: Publisher Brasil.

Illich, I. (1974). La sociedad desescolarizada. [Traducción de Gerardo Espinosa] Barcelona: Barral Editores.

Lens, J.L. (2001). Paulo Freire: su praxis pedagógica como sistema. Instituto Paulo Freire (IPF) de San Pablo. UNCPBA. Buenos Aires: Editorial Yagüe.

Macedo, D. (2000). Una pedagogía antimétodo. Una perspectiva freiriana. Educación XX1, 3, 53-61.

Posada, J.J. (2007). El Pensamiento de Paulo Freire y la construcción de propuestas pedagógicas y curriculares para la Interculturalidad. En Rocha, Y. (Coord.). Tras las huellas de Paulo Freire, (pp. 123-146). Managua, Nicaragua: IPADE/CEAAL.

Santos-Gómez, M. (2008). Ideas filosóficas que fundamentan la pedagogía de Paulo Freire. Revista Iberoamericana de Educación, 46, 155-173.

Torres, C.A. (2001). La voz del biógrafo latinoamericano: una biografía intelectual. En Gadotti, M. y Torres, C.A. (Coord.). Paulo Freire: una biobibliografia, (pp. 97-126). España. Siglo XXI Editores S.A.

Torres, R.Mª (2004). Los múltiples Paulo Freire. En Araujo Freire, A.Ma (Coord.). La pedagogía de la liberación en Paulo Freire, (pp. 193-203). Barcelona: Editorial GRAÓ, de IRIF, S.L.

Verdeja, M. (2015). Aportaciones de la pedagogía de Paulo Freire a la educación intercultural. Posibilidades de aplicación al sistema educativo en Asturias. [Tesis Doctoral] Universidad de Oviedo.

Verdeja, M. y González Riaño, X.A. (2016). Aportaciones de la pedagogía de Paulo Freire a la educación intercultural. Revista Rizoma Freireano, 21 Instituto Paulo Freire de España. Recuperado de: http://www.rizoma-freireano.org/index.php/aportaciones-de-la-pedagogia21 Fecha de consulta 19 de septiembre de 2016. 


\section{Para citar este artículo}

Verdeja Muñiz, M. (2018). Ideas centrales del pensamiento pedagógico político de Paulo Freire: dimensiones de análisis. Revista Fuentes, 20(1), 43-56 [Fecha de consulta: $\mathrm{dd} / \mathrm{mm} / \mathrm{aa}]$.

doi: http://dx.doi.org/10.12795/revistafuentes.2018.v20.11.03 